\title{
Evolving ICT and governance in organizational networks - Conceptual and theoretical foundations
}

\author{
Euripidis Loukis $^{1} \cdot$ Marijn Janssen $^{2} \cdot$ Sharon Dawes $^{3} \cdot$ Lei Zheng $^{4}$
}

Published online: 16 December 2015

(C) Institute of Information Management, University of St. Gallen 2015

\begin{abstract}
Both private and public sector organizations tend to participate in networks in order to gain access to knowledge, skills and resources of other organizations and to create synergies to achieve highly demanding and complex goals they cannot attain individually. The governance of these networks has been recognized as being an important variable influencing organizational network performance. This Special Issue aims to contribute to the investigation and understanding of the relationships between ICT and governance of organizational networks. This introductory paper provides the conceptual and theoretical background. The relationship between network governance and technology is bi-directional; evolutions in ICT enable the development of new types of network collaborations and governance, whereas governance of collaboration networks is critical for the development of complex ICT infrastructures. We argue that network governance should be conceptualized as an evolving socio-technical process shaped by actors and aimed at tackling complex and dynamic contemporary challenges.
\end{abstract}

Marijn Janssen

m.f.w.h.a.janssen@tudelft.nl

Euripidis Loukis

eloukis@aegean.gr

Sharon Dawes

sdawes@ctg.albany.edu

Lei Zheng

zhengl@fudan.edu.cn

1 University of Aegean, 81100 Lesbos, Greece

2 Delft University of Technology, Jaffalaan 5, 2628

BX Delft, The Netherlands

3 University at Albany, 1400 Washington Ave, Albany, NY 12222, USA

4 Fudaan University, 220 Handan Rd, Yangpu, Shanghai, China
Keywords Organizational networks · Network governance Governance $\cdot$ Collaboration

JEL Classifications H11 Structure · Scope $\cdot$ Performance of Government

\section{Introduction to network governance}

An important trend in modern economies and societies is the formation of organizational collaboration networks (OCN) or Inter-Organizational Networks (ION). Both private and public sector organizations tend to participate in networks in order to gain access to knowledge, skills and resources of other organizations which otherwise are out of reach or which they do not want to acquire or possess on their own. By collaborating in networks organizations can achieve demanding and complex goals they cannot attain on their own. Individual organizations play different roles in these networks, which are continually changing shape as different organizations enter or leave them. Thus, networks are dynamic and subject to change. Increasing evidence of organizational networks has led some scholars to claim that the world is becoming a 'network society' (Castells 1996), or even a 'society of networks' (Raab and Kenis 2009).

Globalization, increasing competition, and continuous emergence of new technologies, as well as high and everchanging consumer expectations and demands for valueadded products and services, make it difficult for individual firms to succeed, or even survive, on their own. Consequently, they tend to enter various types of collaboration networks in order to gain access to knowledge, human skills, and the equipment and production facilities of other private and public sector organizations (Capaldo 2014; Rycroft 2007). Examples of various types of organizational networks are innovation 
clusters in which companies bring in different capabilities to innovate or companies working together in supply chains. Contrary to what the name suggests supply chains are often in fact networks of organizations. Whereas, the term supply chain assumes a linear relationship between key activities, there are often many variations. A supply chain view is suitable for analysing the stream of product/service flow, but it does not take into account the many interactions needed for creating and innovating along that flow.

Recent economic crisis and other major problems and challenges of modern society suggest a need to accelerate the development of such networks. In the public sector, government agencies have realized that effective and high-quality public policies for addressing the highly complex problems and needs of citizens and firms, demand collaboration with other public, civic, and private sector organizations (Agranoff and McGuire 2001; Dawes et al. 2009; Dawes et al. 2012; Klievink and Janssen 2009). Furthermore, developments like crowdsourcing and public-private infrastructures and partnerships accelerate the formation of networks.

The prevalence and necessity of inter-organizational networks in both business and government has produced a widevariety of networks serving various purposes. Information infrastructures of businesses and government are increasingly interwoven and there is a need to coordinate their efforts to accomplish social innovation (Klievink and Janssen 2014). Yet we have limited knowledge about the formation, evolution, structure, functions and outcomes of these efforts, as well as their problems, challenges, performance and success factors. More important, perhaps, we know very little about how network governance contributes to performance and ultimate outcomes. The governance of these networks has been recognized as a critical variable that influences strongly their performance and effectiveness (Provan and Milward 1995). A comprehensive definition of governance network which synthesizes several previous definitions is provided by Jones et al. (1997): 'Network governance involves a select, persistent and structured set of autonomous firms (as well as non-profit agencies) engaged in creating products or services based on implicit and open-ended contracts to adapt to environmental contingencies and to coordinate and safeguard exchanges. These contracts are socially, not legally, binding' (p. 904). We therefore define governance as all the mechanisms for preparing, making, implementing and executing decisions in organizational networks.

Technology enables the development of new types of organizational networks, and also different forms of governance. This Special Issue aims to contribute to the investigation of the relationship between ICT and governance of organizational networks. In this introductory paper we provide the conceptual and theoretical foundations of this emerging research domain. In the following section 2 theoretical perspectives on networked governance are proposed. Sections 3, 4, and 5 focus on private, public and private-public sector networks respectively, while section 6 deals with the evolving concepts of network governance. Section 7 provides an overview of the papers of this Special Issue. The final section 8 offers concluding thoughts and future directions.

\section{Theoretical perspectives on networked governance}

In the modern interconnected world the working of networks has become critically important in both public and private sectors for the design, production and innovation of complex products and services. The effectiveness and efficiency of organizations has become more dependent on the efficient and effective operation of networks, rather the efficiency and effectiveness of individual organizational functions. Networks today consist of a variety of heterogeneous organizations, which have different resources and capabilities, objectives, business partners, software applications, technical infrastructures, readiness and staff. Network-based governance of interorganizational exchange and collaboration is therefore a multifaceted and complex topic that is addressed differently by different researchers. All these aspects contribute to a thriving research area that can be tackled from different theoretical perspectives and kernel theories from public administration, economics and political science.

In economic theory discussion at the macro level has moved from a debate between hierarchies and markets (Malone et al. 1987) has moved toward the idea that networks prevail (Clemons et al. 1993b; Clemons and Row 1992). This research aims to examine which conditions and factors might result in the development of inter-organizational networks as well as the advantages of networks compared to the two main alternatives: markets or hierarchies. Organizations will not perform tasks internally when the cost of organizing an extra transaction within the boundaries of the enterprise becomes higher than when someone else (an external actor) performs the transaction. Transaction costs result from interactions among parties and exist because of friction in economic systems (Coase 1937; Williamson 1975). Coase (1937) argues that the main reason to set up a business is to avoid some transaction costs, whereas Williamson (1975) sees asset specificity, in which assets are specific to each organization, as the main reason for the existence of firms. Asset specificity is the extent to which investments made to support a particular transaction have a higher value for one organization than for others. This work predominately concentrates on the interaction among organizations and the associated transaction costs. Based on transaction cost economics and social network theory, Jones et al. (1997) proposed "A general theory of network governance: Exchange conditions and social mechanisms" in which network governance is a response to asset specificity, demand uncertainty, task complexity and task 
frequency. Clemons et al. (1993a) argue further that IT can reduce coordination costs without increasing the associated risks of working in organizational networks.

Economic transactions also affect the social relationships among organizations. In social relationship theory the relationships among participants are studied at the micro level. Principal-agent theory deals with the relationship between the principal and agent based on the division of labour, information asymmetry, and environment and partner behaviour (Jensen and Meckling 1976). In this stream of research trust plays a crucial role affecting interorganizational network relationships. Bardach and Eccles (1989) view trust as an organization's expectation that another firm will not act opportunistically. Trust among participating organizations pertains to both informal relationships and formal governance mechanisms, such as service level agreements, contracts and benchmarks. Interorganizational trust influences the type of governance, which in turn influence the performance of exchange relationship (Gulati and Nickerson (2008)). Three kinds of trust are salient in these social relationships. Calculus-based trust (Williamson 1993) rests on information-based, rational decisions about the organization or person to be trusted. Identity-based trust (Coleman 1990) stems from familiarity and repeated interactions among the participants. Identitybased trust also emerges from joint membership in a profession, a team, a work group, or a social group. Institution-based trust (Gulati 1995; Ring and Van de Ven 1992) rests on social structures and norms, such as laws and contracts, that define and limit acceptable behavior. All three kinds of trust may be needed to assure the sustainability organizational networks as well as their capacity to resolve conflict and solve managerial problems.

Public administration theory covers networked governance (Hartley 2005) by focusing on new public management (Hood 1991), new public governance (Osborne 2006) and public value management (Stoker 2006). The focus here is on networks of public organizations, and sometimes even on constellations of public networks, that collaborate to provide services or to innovate in ways that are advantageous compared to markets or hierarchies. Furthermore, they focus on the coordination of these networks including the role of Network Administrative Organization (NAO) (Provan and Milward 2001). A NAO is sometimes called a network broker, third party, network orchestrator or (network) intermediary, and it is aimed at creating and coordinating organizational networks. From this research perspective, multiple individual relationships are analysed stressing the realization of join action, addressing tension, making trade-offs in governance arrangements and assessing the impact on organizational structure and behaviour.

In political theories the focus is on the role of power, viewing organizations as political entities (Pfeffer 1981). Networks are negotiated and participating firms use their power to influence the network and to strengthen their own positions. Network governance is created by the shared objectives of the organizations responsible of each group of activities. They view these networks as an arena in which there is a continuous struggle about power. Governance structures therefore often reflect the distribution of power in an organizational network. Political governance research is directed towards the analysis of the positioning of organizations, their interests and their possibilities to exercise power. Exercising power might be limited in certain types of networks due to complex tasks having high human task asset specificity (Jones et al. 1997). The use of power might be contra-productive. Furthermore as new organization enter or leave the network, the power balance can change. In addition, new technologies might influence the power balance as some tasks might become obsolete and others more central. From this view, shared values and norms and joint objectives can be used to guide network participants.

Governance theories in general capture various aspects, from culture to the paths taken to arrive at formal defined decision making mechanisms. In a supportive culture, persons might be empowered to take the initiative and take decisions with discretion, whereas in a more hierarchical culture the focus is on following the rules and ensuring that the right persons take the decisions. At the heart of governance is defining the mechanisms for arriving at decisions, whereas management is the taking of the actual decisions. All these theories provide complementary insights into the governance of organizational networks and have been employed in various studies.

\section{Private sector networks}

Private sector firms increasingly tend to work together with other for-profit and non-profit organizations, forming together various types of organizational business networks (Short and Venkatraman 1992), innovation networks (Salavisa et al. 2012), and even public-private networks (Grimsey and Lewis 2007). Majava et al. (2013) identify several types of private sector networks, such as business networks, clusters, ecosystems, innovation hubs, keiretsu, and triple-helix, which differ in terms of members, goals, coordination, boundaries, change dynamism, nature of relationships, and role of knowledge. Usually these networks involve suppliers, customers, partners, and even universities and government agencies that collaborate in order to design, produce and promote innovative products and services. The essential characteristic of these networks is that a number of organizations work together in a loosely coupled structure that might vary over time. Although there is a shared objective that motivates the formation of the network, these organizations have their own interest and stakes, and this often gives rise to problems in the functioning of the network and the collaboration. Networks have become 
of critical importance in the modern economy, and competition in many industries tends to be more among such collaboration structures than among individual firms (Rycroft 2007; Busquets 2010; Zeng et al. 2010).

Networks are particularly important as 'conduits' for moving and processing knowledge, and they gradually become the main 'locus' of combination of diverse knowledge and complementary resources, and creation of novel knowledge and innovation at a network level (Capaldo 2014; Mancinelli and Mazzanti 2009; Salavisa et al. 2012; Zeng et al. 2010). Networks offer substantial comparative advantages in coordinating knowledgeintensive activities at the inter-organizational level; their social mechanisms increase the propensity of network participants to share relevant information, to transfer knowledge across organizational boundaries, and to generate new knowledge. Business networks have become particularly important in the modern economy due to a fundamental change in the way firms design and implement innovation: while previously this was predominantly an internal task, in the last decade it has increasingly become a more 'open' and collaborative process, involving extensive interactions with other cooperating firms, such as suppliers, customers, intermediaries, and also public agencies (Salavisa et al. 2012; Zeng et al. 2010). The participation of an organization in networks bring benefits like access to complementary resources and capabilities which are otherwise out of research, access to new markets and technologies, diversity of knowledge, and also opportunities to achieve economies of scale, to share the costs, investment and risks of firm's activities, and to cope with market, product and technological complexities (e.g. Salavisa et al. 2012; Zeng et al. 2010)..

Business networks involve extensive exchange of information and knowledge among their members, and also require extensive coordination of their activities. In particular, relationships among firms as part of such structures necessitate specific coordination actions at three layers (Baraldi and Nadin 2006): 'activity links' (i.e. mutual adaptations in their activities), 'resource ties' (i.e., technical connections and mutual orientations of their physical and organizational resources) and 'actor bonds' (i.e. social interactions between individuals and organizational units of collaborating firms). These coordination actions require extensive exchanges of information, both 'structured' and 'unstructured', which can be greatly supported through the use of appropriate ICTs. However, limited research has been conducted concerning the effects of various ICTs on the development, operation, governance, efficiency and effectiveness of private sector networks. This Special Issue aims to contribute to filling this research gap.

\section{Public sector networks}

Public sector networks can serve various purposes including providing services and enabling policy-making. Public service networks are collaborative, inter-organizational networks that have become a common way to deliver public services (Provan 1993). Service delivery can include activities and sub-processes executed by a variety of public organizations and the dependencies among the activities of these agencies need to be managed. Networks of government agencies are also formed for integrated service delivery, using a 'one stop shop' model that offers a single physical or virtual place for citizens to access multiple services produced by different government agencies (Klievink and Janssen 2009).

Governments traditionally rely on the input and cooperation with society in 'policy networks' (Rhodes 1997). Government agencies realized that they needed the knowledge, the resources and the cooperation of non-state actors, initially economic actors and later other social actors as well. In policy networks the non-state actors provide to the state actors on one hand information, knowledge and expertise, and on the other hand support for the formulation and implementation of public policies; in return the former have the opportunity to influence the public policies, the legislation, and the allocation of government financial resources towards directions that are beneficial to them. Changes are sensed by one or more network actors, who inject new ideas to the network, which are then transmitted to the other actors. In addition, external context changes lead to changes in a policy network's composition, entry of new actors, and also changes in the levels of influence of the existing actors. As a result, networks need to be adaptive and to reflect such changes in their governance.

Furthermore, knowledge networks are developed which involve sharing knowledge and information across traditional boundaries in order to address needs that no single organization or jurisdiction can handle alone (Dawes et al. 2012). These boundaries may lie between organizational units, different public departments or ministries, levels of government, or geographic regions, among others. Such networks are complex and dynamic socio-technical systems involving mutual relationships, policies, information, knowledge, processes, and technologies. Furthermore, transnational public sector knowledge networks are also emerging, allowing government agencies from one country to exchange information and knowledge with 'counterparts' from other countries in order to address global issues such as public health emergencies, environmental monitoring and protection, and international migration (Dawes et al. 2012).

Public sector networks are important for addressing pressing social problems and needs, such as health and social needs of children and people with mental illnesses (Provan and Milward 1995), unemployment and workforce development 
(Herranz 2008), regional economic development (Teisman and Klijn 2002), and regulatory compliance (Bharosa et al. 2013). Government agencies have also recently begun to exploit Web 2.0 social media (e.g. Facebook, Twitter, etc.) in order to create networks with civil society organizations and citizens, for exploiting their knowledge for the design or improvement of public policies and services, leading to a gradual shift towards 'co-production' of public services (Ferro et al. 2013; Linders 2012; Nam 2012).

\section{Public-private sector networks}

Policy networks that typically cross the public and private sectors are often considered an important model of future organization and coordination that can enable businesses, governments, and civil society to collaborate. In this networks companies have to report some information to government, but can also voluntarily cooperate with governments (Bharosa et al. 2013). Governance of these networks requires communication, decision making, power sharing and coordination mechanisms. Governance encounters many challenges and processes depend on the changes in the cultural, normative, and regulative structures (Klievink and Janssen 2014). All these forms of cooperative networks among government agencies, private sector firms, civil society and citizens rely critically on traditional ICTs, as well as on the Internet and Web 2.0 social media, for their operation. Consequently, such networks need a sound ICT-infrastructure to support critical functions. Especially the transnational public sector networks can be significantly supported by 'transnational IS', whose development and management however face significant challenges and conflicts (Rukanova et al. 2015). While some research has been done on the nature and effects of networks in the public and private sectors separately, our knowledge about the effects of ICT on them has not been sufficiently researched, so this Special Issue aims to contribute to filling this research gap.

Both companies and governments have started sharing services produced in organizational units called 'shared services centers', which provide pre-defined services to several government agencies, generating significant benefits from economies of scale, reduced costs and higher expertise and service quality (Janssen and Joha 2006). This results in the sourcing of functions to other parties which enables organizations to focus on their core business.

\section{Governance of networks}

Governance is necessary to deal with a wide variety of situations in networks. This can be operational execution but can also be related to the willingness to share crucial data with each other and the handling of conflict. Organizational and national contexts provide potential for conflict (Rukanova et al. 2015) and governance mechanisms are necessary to handle a wide variety of issues. Governance mechanisms change over time and one reason for this is that the problems that are tackled by the governance mechanism also change over time. As such, to understand the creation and evolution of governance mechanisms it is essential to know what the problems are that need to be tackled by those mechanisms.

Sambamurthy and Zmud (1999) identify three primary modes of IT governance; centralized, decentralized and the federal mode. In general there are three kinds of governance mechanisms: (1) decision-making structures, (2) alignment processes and (3) formal communications (Weill and Ross 2005). Relationship-specific processes need to be designed and implemented in business networks (Heinrich et al. 2011). Also the use of contracts and agreements are necessary to formalize expectations. Nevertheless collaboration in networks is often based on trust. Contracts and formal agreements are no substitute for trust as not everything can be covered in such agreements and overly strict contract provisions might result in strategic self-serving behaviour. Too much detail in a contract might even block instead of facilitate the collaboration.

Governance of networks is inherently complex. Actors that participate in networks have power, established social and contractual relationships, and can influence decision making. Nevertheless organizations are dependent on each other as networks are a vehicle for accomplishing their objectives and might be key to their survival. When cooperating in networks, an organization must not only govern and manage its own internal operations, but it must also arrange and manage participation in multi-organization networks. Capabilities for the management of networks are different from that needed for managing a single organization (Agranoff and McGuire 1998; Klievink and Janssen 2009).

Governance has to deal with the complexities, interdependencies and dynamics among the organizations operating in networks. These complexities, interdependencies and dynamics complicate decision making as responsibilities might shift, decisions made by one organization might impact other organizations, the consequences of such decisions are often not clear and there is often no uniform way of making networklevel decisions. Governance mechanisms used might be different each time and context dependent. The main players have to interact with each other, resolve possible conflicts and negotiate about desired outcomes. Although often no formal governance processes exist to include new players in the network, networks can and do evolve as new organizations join and others leave. In this way the organizational network co-evolves over time with all kinds of internal and external changes.

Governance mechanisms therefore should be able to deal with a variety of issues and changes that might arise. Figure 1 


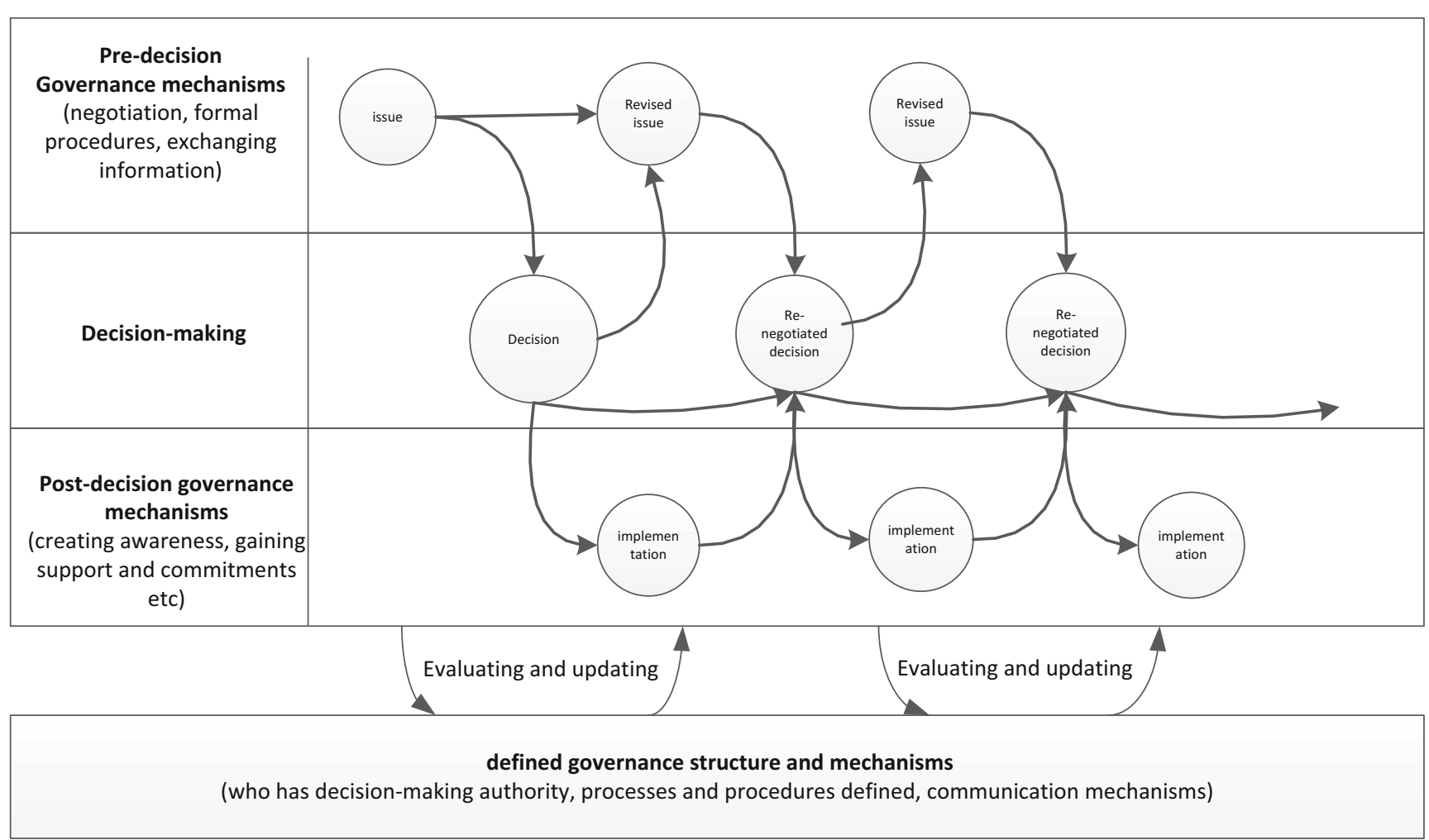

Fig. 1 Network governance conceptualized as a continuous process

shows a conceptualization of governance as a process evolving over time. The existence of some initial issues results in the use of predefined or informal governance mechanisms. Ultimately a decision is made to deal with the contemporary issues at stake. The decision might be final and communicated and implemented using other governance mechanisms, or the decision might be challenged and result in a revised issues and the process started over again. As such there is a continuous loop between issues, the use of various kinds of governance mechanisms, informal processes and decisions, implementation, and the adaption of governance mechanisms. Furthermore decisions and the underlying decision-making process are evaluated for facilitating organizational learning.

The bottom of Fig. 1 shows that there is a defined governance structure and accompanying mechanisms that can be updated due to the shifting needs for governance. The use of governance mechanisms differ according to the situation. There might be defined governance mechanisms like monthly meetings between the organizational partners, procedures for dealing with changes and the communication of changes (like interfaces between systems) and so on. Nevertheless, formal mechanisms might depend on variables like the maturity of the network, its purpose, the software systems used, the existence and form of leadership and other variables. Furthermore, in the process of implementation the network may become aware that its governance mechanisms are insufficient for some issues making changes necessary. As such, there is a continuous cycle to update predefined governance structure, which in turn is accomplished by employing governance mechanisms resulting in an evolving set of recursive relationships. In short, we argue that governance should be conceptualized as a dynamic and problem-driven process which is shaped by continuous interaction among actors.

\section{Overview of papers}

This Special Issue contains three papers addressing different aspects of relationships between governance of networks and ICT. The first paper concerns the governance of a new network that has been developed by a government agency by exploiting a new revolutionary ICT: Web 2.0 social media. It shows that networked governance using these new communication channels (microblogs) in emergency and crisis management is a key capability necessary for effective response. The paper by Qingguo Meng, Nan Zhang, Xuejiao Zhao, Fangling Li and Xin Guan titled "The Governance Strategies for Public Emergencies on Social Media and Their Effects: A Case Study Based on the Microblog Data" investigates strategies for networked governance based on micro blogs. Microblogs 
are a type of social media application that provides rich information. The authors propose a classification of government strategies on social media into five categories (introducing, appealing, explaining, rumor-refuting, and decision-making) and describes the impact that these strategies can have. The results of the analysis show that different government strategies are applied to different phases of the incident and that the responses of the public also vary during different periods.

The second paper of this Special Issue concerns business networks developed for an important and highly complex new ICT-based sector: e-business. It examines the geographic concentration of the e-business sector of China, and analyses factors that influence it. The paper is titled "The Geographic Concentration of China's e-business Enterprises: Where They Gather and Why", by Yu Sun, Xingxuan Kuang and Dazhi Sun. It examines the main clusters of this sector, and identifies three emerging ones, which are beyond the commonly mentioned major high-technology regions of China. The authors conclude that regional economic status and ICT infrastructure are necessary conditions for the creation of such a cluster, but not sufficient conditions. They authors also found that China's e-business sector differs from the corresponding one of the United States. China's business sector is affected by the capital effect and also the firms' founders' social relationships, but it does not depend on local public sectors' deliberate efforts to encourage business development and growth. This finding has considerable governance implications.

The final paper focuses on the relationships between ICT and network governance, and investigates how evolutions in the former affect the latter. The paper is titled "How and Why Network Governance Evolves: Evidence from a Public Safety Network", by Dax Jacobson. The paper investigates the evolution of governance over the $40+$ year lifespan of a public sector network (the National Justice Network of USA) and examines its association with technology evolution. Jacobson concludes that this network remained successful because the governance of it organization was able to make governance changes in response to new technologies. The research presented in this paper provides evidence that technology and governance do interact and that the governance consequently evolves. Findings indicate the value in considering technology affordances, constraints and actualization in the evolution of network governance. It shows that when new technology arrives decision makers need to ensure that they change the governance of the network accordingly.

\section{Conclusions}

Economic theory, social relationship theory, public administration theory and political theories provide complimentary insights into the governance of organizational networks.
Nevertheless, empirical study of actual governance of networks has been given scant attention and provides limited insight. When creating a network, incentives and clear prospects for benefits to the participating organizations are necessary. The network development process is difficult and requires time to create the necessary authority structures, procedures and mechanisms for collaboration that are necessary for formal governance arrangements to ensuring coherency and high performance. Organizational networks, however, are not static entities. They co-evolve with changes in technology, and especially in ICT, and the demands of the problems they address. The ways in which these factors interrelate determine what is manageable and how a network is shaped. Thus, we need to develop a better understanding of both the social and technical factors that influence governance and also how governance influences network performance. We argue that governance should be conceptualized as an evolving and problem-driven socio-technical process that is shaped by interactions among the diverse actors in organizational networks. Uncertainty, change, and experience all contribute to continuous evolution in the governance of these organizational networks. More research, like the studies presented in the papers of this Special Issue, is needed to build an integrated socio-technical theory of network governance.

\section{References}

Agranoff, R., \& McGuire, M. (1998). Multinetwork management: collaboration and the hollow state in local economic policy. Journal of Public Administration and Theory, 8(1), 67-91.

Agranoff, R., \& McGuire, M. (2001). Big questions in public network management research. Journal of Public Administration Research and Theory, 11(3), 295-326.

Baraldi, E., \& Nadin, G. (2006). The challenges in digitalising business relationships - the construction of an IT infrastructure for a textilerelated business network. Technovation, 26(10), 1111-1126.

Bharosa, N., Janssen, M., Van Wijk, R., De Winne, N., Van der Voort, H., Hulstijn, J., et al. (2013). Tapping into existing information flows: the transformation to compliance by design in business-togovernment information exchange. Government Information Quarterly, 30(1), S9-S18.

Bardach, J., \& Eccles, R. (1989). Price, authority, and trust: from ideal types to plural forms. Annual Review of Sociology, 15, 97-118.

Busquets, J. (2010). Orchestrating smart business network dynamics for innovation. European Journal of Information Systems, 19(4), 481493.

Capaldo, A. (2014). Network governance: a cross-level study of social mechanisms, knowledge benefits, and strategic outcomes in jointdesign alliances. Industrial Marketing Management, 43(4), 685-703.

Castells, M. (1996). The Rise of the Network Society. London: Blackwell.

Clemons, E. K., \& Row, M. C. (1992). Information technology and industrial cooperation: the changing economics of coordination and ownership. Journal of Management Information Systems, 9(2), 9-28.

Clemons, E. K., Reddi, S. P., \& Row, M. C. (1993a). The impact of information technology on the organization of economic activity: the "Move to the middle" hypothesis. Journal of Management Information Systems, 10(2), 9-35. 
Clemons, E. K., Reddi, S. P., \& Row, M. C. (1993b). The impact of information technology on the organization of economic activity: the "move to the middle" hypothesis. Journal of Management Information Systems Management, 10(2), 9-35.

Coase, R. (1937). The nature of the firm. Economia, 4, 386- 405.

Coleman, J. S. (1990). Foundations of social theory. Cambridge: Belknap Press of Harvard University Press.

Dawes, S. S., Cresswell, A. M., \& Pardo, T. A. (2009). From "Need to Know" to "Need to Share": tangled problems, information boundaries, and the building of public sector knowledge networks. Public Administration Review, 69(3), 392-402.

Dawes, S. S., Gharawi, M. A., \& Burke, G. B. (2012). Transnational public sector knowledge networks: knowledge and information sharing in a multi-dimensional context. Government Information Quarterly, 29(Supplement 1), S112-S120. doi:10.1016/j.giq.2011. 08.002 .

Ferro, E., Loukis, E. N., Charalabidis, Y., \& Osella, M. (2013). Policy making 2.0: from theory to practice. Government Information Quarterly, 30(4), 359-368.

Grimsey, D., \& Lewis, M. K. (2007). Public private partnerships: the worldwide revolution in infrastructure provision and project Finance. Cheltenham: Edward Elgar Publishing Limited.

Gulati, R. (1995). Does familiarity breed trust? The implications of repeated ties for contractual choice in alliances. Academy of Management Journal, 38(1), 85-112.

Gulati, R., \& Nickerson, J. A. (2008). Interorganizational trust, governance choice, and exchange performance. Organization Science, 19(5), 688-708. doi:10.1287/orsc.1070.0345.

Hartley, J. (2005). Innovation in governance and public services: past and present. Public Money \& Management, 25(1), 27-34. doi:10.1111/j. 1467-9302.2005.00447.x.

Heinrich, B., Zellner, G., \& Leist, S. (2011). Service integrators in business networks - the importance of relationship values. Electronic Markets, 21(4), 215-235. doi:10.1007/s12525-011-0075-x.

Herranz, J. (2008). The multisectoral trilemma of network management. Journal of Public Administration Research and Theory, 18(1), 1-31.

Hood, C. (1991). A public management for all seasons? Public Administration 69(1):3-19. doi: 10.1111/j.1467-9299.1991. tb00779.x.

Janssen, M., \& Joha, A. (2006). Motives for establishing shared service centers in public administrations. International Journal of Information Management, 26(2), 102-116.

Jensen, M., \& Meckling, W. (1976). Theory of the Firm: managerial behavior, agency costs, and capital structure. Journal of Financial Economics, , 5, 305-360.

Jones, C., Hesterly, W. S., \& Borgatti, S. P. (1997). A General theory of network governance: exchange conditions and social mechanisms. The Academy of Management Review, 22(4), 911-945. doi:10.2307/ 259,249 .

Klievink, B., \& Janssen, M. (2009). Realizing joined-up government. Dynamic capabilities and stage models for transformation. Government Information Quarterly, 26(2), 275-284.

Klievink, B., \& Janssen, M. (2014). Developing multi-layer information infrastructures: advancing social innovation through public-private governance. Information Systems Management, 31(3), 240-249. doi:10.1080/10,580,530.2014.923268.

Linders, D. (2012). From e-government to we-government: defining a typology for citizen coproduction in the age of social media'. Government Information Quarterly, 29(4), 446-454.

Majava, J., Isoherranen, V., \& Kess, P. (2013). Business collaboration concepts and implications for companies. International Journal of Synergy and Research, 2(1), 23-40.

Malone, T. W., Yates, J., \& Benjamin, R. I. (1987). Electronic markets and electronic hierarchies. Communications of the ACM, 30(6), 484-497.
Mancinelli, S., \& Mazzanti, M. (2009). Innovation, networking and complementarity: evidence on SME performances for a local economic system in North-Eastern Italy. The Annals of Regional Science, 43(3), 567-597.

Nam, T. (2012). Suggesting frameworks of citizen-sourcing via government 2.0. Government Information Quarterly, 29(1), 12-20.

Osborne, S. (2006). The new public governance? Public Management Review, 8(3), 377-387.

Pfeffer, J. (1981). Power in Organizations.

Provan, K. G. (1993). Embeddedness, interdependences, and oppotunism in organizational suppier-buyers networks. Journal of management, 19(4), 841-856.

Provan, K. G., \& Milward, H. B. (1995). A preliminary theory of interorganizational network effectiveness: a comparative study of four community mental health systems. Administrative Science Quarterly, 40, 1-33.

Provan, K. G., \& Milward, H. B. (2001). Do networks really work? a framework for evaluating public-sector organizational networks. Public Administration Review, 61(4), 414 423. doi:10.1111/00333352.00045.

Raab, J. K., \& Kenis, P. (2009). Heading toward a society of networks: empirical developments and theoretical challenges. Journal of Management Inquiry, 18(3), 198-210.

Rhodes, R. A. W. (1997). Understanding Governance: Policy Networks, Governance, Reflextvity and Accountability. Buckingham: Open University Press.

Ring, P. S., \& Van de Ven, A. H. (1992). Structuring cooperative relationships between organization. Strategic Management Journal, 13(7), 483-498. doi:10.1002/smj.4250130702.

Rukanova, B., Wigand, R. T., van Stijn, E., \& Tan, Y.-H. (2015). Understanding transnational information systems with supranational governance: a multi-level conflict management perspective. Government Information Quarterly, 32(2), 182-197. doi:10.1016/ j.giq.2014.12.003.

Rycroft, R. W. (2007). Does cooperation absorb complexity? Innovation networks and the speed and spread of complex technological innovation. Technological Forecasting \& Social Change, 74(5), 565578.

Salavisa, I., Sousa, C., \& Fontes, M. (2012). Topologies of innovation networks in knowledge-intensive sectors: Sectoral differences in the access to knowledge and complementary assets through formal and informal ties. Technovation, 32(6), 380-399.

Sambamurthy, V., \& Zmud, R. W. (1999). Arrangements for information technology governance: a theory of multiple contingencies. MIS Quarterly, 23(2), 261-290.

Short, J., \& Venkatraman, N. (1992). Beyond business process redesign: redefining Baxter's business network. Sloan Management Review, 34(1), 7-21.

Stoker, G. (2006). Public value management: a new narrative for networked governance? The American Review of Public Administration, 3(1), 41-57.

Teisman, G. R., \& Klijn, H. H. (2002). Partnership arrangements: governmental rhetoric or governance scheme? Public Administration Review, 62(2), 197-205.

Weill, P., \& Ross, J. W. (2005). A matrixed approach to designing IT governance. MIT Sloan Management Review, 46(2), 26-34.

Williamson, O. E. (1975). Market and hierarchies, analysis and antitrust implications. a study in the economics of internal organization. New York: Macmillan.

Williamson, O. E. (1993). Calculativeness, trust, and economic organization. Journal of Law and Economics, 36(1), 453-486.

Zeng, S. X., Xie, X. M., \& Tam, C. M. (2010). Relationship between cooperation networks and innovation performance of SMEs. Technovation, 30(3), 181-194. doi:10.1016/j.technovation.2009. 08.003 . 